Research Article

\title{
Insight into Anticorrosion Mechanism of Ampicillin on Mild Steel in Acidic Environment: A Combined Experimental and Theoretical Approach
}

\author{
Tuan Dinh, ${ }^{1}$ Nguyen Minh Thong $\mathbb{D}^{2}$ Dinh Quy Huong $\mathbb{D}^{3}{ }^{3}$ Trinh Le Huyen $\mathbb{D}^{4}$, \\ Tran Duc Manh $\left(\mathbb{0},{ }^{5}\right.$ Phan Tu Quy $\left(\mathbb{0},{ }^{6}\right.$ Tran Xuan Mau ${ }^{1},{ }^{1}$ and Pham Cam Nam $\left(\mathbb{C}^{4}\right.$ \\ ${ }^{1}$ Department of Chemistry, Hue University of Sciences, Hue University, 77 Nguyen Hue, Hue, Vietnam \\ ${ }^{2}$ The University of Danang, Campus in Kon Tum, 704 Phan Dinh Phung, Kon Tum, Vietnam \\ ${ }^{3}$ Department of Chemistry, Hue University of Education, Hue University, Hue, Vietnam \\ ${ }^{4}$ Department of Chemistry, The University of Danang-University of Science and Technology, 54 Nguyen Luong Bang, Lien Chieu, \\ Danang, Vietnam \\ ${ }^{5}$ The University of Danang-University of Science and Education, Da Nang 550000, Vietnam \\ ${ }^{6}$ Department of Natural Sciences \& Technology, Tay Nguyen University, Buon Ma Thuot 630000, Vietnam
}

Correspondence should be addressed to Nguyen Minh Thong; nmthong@kontum.udn.vn, Tran Duc Manh; tdmanh@ued.udn.vn, and Pham Cam Nam; pcnam@dut.udn.vn

Received 14 July 2021; Revised 10 September 2021; Accepted 15 September 2021; Published 1 October 2021

Academic Editor: Hua-Bing Li

Copyright $@ 2021$ Tuan Dinh et al. This is an open access article distributed under the Creative Commons Attribution License, which permits unrestricted use, distribution, and reproduction in any medium, provided the original work is properly cited.

The corrosion inhibition of mild carbon steels in an acidic environment by using ampicillin (AMP) has been evaluated based on experimental and quantum chemistry techniques. The experimental results indicate that the inhibition efficiency goes up at higher AMP concentration. The highest inhibition efficiency reaches $84.9 \%$ for polarization measurement and $90.1 \%$ for electrochemical impedance spectroscopy with the inhibitor of concentration $100 \mathrm{ppm}$ at $298 \mathrm{~K}$. The surface characteristics (SEM) also reconfirm the steel corrosion inhibition ability of AMP. Some important chemical factors such as $E_{\text {HOMO }}$ (highest occupied molecular orbital energy), $E_{\mathrm{LUMO}}$ (lowest unoccupied molecular orbital energy), $\Delta E_{L-H}$ (energy gap), and Fukui functions were calculated based on the optimized configuration of AMP at the theoretical level of B3LYP/6-31+G(d,p). Moreover, Monte Carlo and molecular dynamics simulations were used to analyze the absorption behavior of inhibitor on the surface of $\mathrm{Fe}(110)$, which supplies the mechanism of inhibition corrosion processes. The obtained results showed that AMP is considered to be a potential corrosion inhibitor for mild steel in $1 \mathrm{M} \mathrm{HCl}$ medium. Moreover, the protonated state of AMP plays an important role in the protection of Fe surface against the corrosive process.

\section{Introduction}

Corrosion of metals is a key problem in industrial processes that has fascinated a large number of studies [1-4]. Because mild steel has good mechanical strength and low cost, it is widely used for industrial applications [5]. Besides, the acidic medium is usually utilized in industrial processes such as metal surface cleaning. This is the cause of the steel corrosion to be enhanced [6-8]. To prevent unexpected metal dissolution, inhibitors are used against corrosion [3]. Most inhibitors are selected from organic species containing $\pi$-systems and heteroatoms such as $\mathrm{N}, \mathrm{O}, \mathrm{S}$, and $\mathrm{P}$ in the aromatic rings or having a long carbon chain $[9,10]$.

The advantage of many synthetic organic compounds is that they are cheap and possess efficient anticorrosive activity, but their disadvantage is that they are harmful to humans and pollute the environment. To remedy this situation, green corrosion inhibitors originated from natural products and drug compounds are preferred because of their eco-friendly and nontoxic nature [11]. 
Antibiotics are used for the treatment of human and animal diseases. However, the antibiotic residues may be released into the environment through wastewater effluent, medical waste, etc., which are the causes of environmental pollution. Fortunately, these compounds have heteroatoms in their structures, as mentioned in the previous paragraph, which can get effectively absorbed on the metal surface and thus protect it from corrosion $[2,12,13]$. In this context, one of the fields of green chemistry is renewable raw materials to protect the metallic surface for reducing the environmental impact and the wastes.

Practically, the obtained results show that ampicillin (AMP) can be used as the metal protecting compound in acidic media $[8,13,14]$. In the acidic solutions, AMP molecule can coexist in both neutral and protonated forms because it contains heteroatoms such as oxygen, nitrogen, and sulfur. In this regard, rarely reports have considered the protonated form of AMP and made clear the mechanism of corrosion protection in the acidic environment at the molecular level. The structure of AMP is shown in Figure 1 with the commercial name of $(2 S, 5 R, 6 R)-6-([(2 R)-2$-amino-2phenylacetyl]amino)-3,3-dimethyl-7-oxo-4-thia-1-azabicyclo[3.2.0] heptane-2-carboxylic acid.

Normally, experimental techniques have been used to determine corrosion protection activity. Furthermore, computational methods based on density functional theory (DFT), molecular dynamics (MD) simulation, and Monte Carlo (MC) simulation have also been used widely to clarify the anticorrosive mechanism in recent years [15]. Thus, this technique is a helpful tool to obtain essential information such as molecular reactivity, charge transfer, preferred adsorption configuration, inhibitor/metal interface interaction, and the relationship between structural characteristics and anticorrosive efficiency.

In the current study, a combination of the experimental and theoretical approaches to exploit the anticorrosive mechanism of AMP was carried out and presented in detail. In the first part, electrochemical measurements and scanning electron microscopy were utilized to evaluate the corrosion inhibitor effect of AMP at the various concentrations in $1 \mathrm{M} \mathrm{HCl}$. In the second part, three computational methods (DFT, MC, and MD) were used to provide vital insights into the inhibition process at the molecular level.

\section{Experimental Details}

2.1. Materials. The major ingredients of the mild steel CT3 (Dana Italia) include (in percentage mass) $\mathrm{C}=0.2682$, $\mathrm{Mn}=0.5798, \quad \mathrm{Si}=0.2653, \quad \mathrm{~S}=0.0211, \quad \mathrm{Ni}=0.0685$, $\mathrm{Cr}=0.0946, \quad \mathrm{Cu}=0.2340, \quad \mathrm{Mo}=0.0096, \quad \mathrm{~V}=0.0041$, $\mathrm{P}=0.0226$, and balance $\mathrm{Fe}$. The specimens with cylindrical shape and exposing $1 \mathrm{~cm}^{2}$ surface area were prepared for electrochemical experiments.

The aggressive solution was prepared by diluting 37\% $\mathrm{HCl}, d=1.19 \mathrm{~kg} / \mathrm{L}$ (purchased from Merck), with distilled water. The investigated concentrations of AMP (SigmaAldrich) are 20, 40,60, 80, and 100 ppm, respectively.
2.2. Electrochemical Measurements. Potentiostat PGS-HH5 equipment (manufactured by Vietnam Academy of Science and Technology) with a three-electrode system including the reference electrode $(\mathrm{Ag} / \mathrm{AgCl})$, the counter electrode (stainless steel), and the working electrode (mild steel CT3) was used for electrochemical studies.

After the specimen was immersed in the $1 \mathrm{M} \mathrm{HCl}$ solution for 60 minutes, potentiodynamic polarization investigations were performed with a scanning rate of $1 \mathrm{mV} / \mathrm{s}$ in the potential range of $-600 \mathrm{mV}$ to $-300 \mathrm{mV}$. All electrochemical experiments were set up at $298 \mathrm{~K}$ and stabilized by the Stanhope-Seta, Model 22101-4, with $\pm 0.1^{\circ} \mathrm{C}$ accuracy. The inhibition efficiency (\%IE) values were obtained by using the following equation:

$$
\% \mathrm{IE}=\frac{I_{\text {corr }}^{0}-I_{\text {corr }}}{I_{\text {corr }}^{0}} \times 100,
$$

where $I_{\text {corr }}^{0}$ and $I_{\text {corr }}$ are the corrosion current density in the absence and presence of inhibitor, respectively.

The parameters of electrochemical impedance spectroscopy (EIS) were performed at open-circuit potential with an alternating current amplitude of $10 \mathrm{mV}$ using a frequency region of $10 \mathrm{mHz}-100 \mathrm{kHz}$.

The EIS was recorded with Zahner Zennium (IM6) using the Thales 4.5 software package. Anticorrosion behavior $(\eta \%)$ of EIS experiments was expressed by the following equation:

$$
\eta \%=\frac{R_{\mathrm{ct}}-R_{\mathrm{ct}}^{\prime}}{R_{\mathrm{ct}}} \times 100,
$$

where the charge transfer resistance corresponding to without/with AMP is $R_{\mathrm{ct}}^{\prime}$ and $R_{\mathrm{ct}}$, respectively $[16,17]$.

2.3. Surface Analysis. Mild steel samples were prepared and then immersed in $1 \mathrm{M} \mathrm{HCl}$ with the AMP concentrations of $0,20,40,60,80$, and $100 \mathrm{ppm}$ in 6 hours. Thereafter, the specimens were washed with distilled water, degreased with acetone, wiped with a clean towel paper, and finally airdried. The surfaces of specimens were observed by using an EVO-ZEISS scanning electron microscope (SEM) at the Analysis Centre for Import Export Products, Danang Branch (Vietnam).

\subsection{Computational Chemistry Approaches}

2.4.1. Quantum Chemical Calculation. The B3LYP/6$31+G(d, p)$ method was utilized to calculate the corrosion descriptors for both neutral and protonated forms of AMP. The solvent effect on the enthalpies of this system was estimated by the IEF-PCM solvation method [18, 19]. Gaussian 09 software was used for all calculations [20].

Based on the above, the reactions are described as follows:

$$
\mathrm{AMP}+\mathrm{H}^{+} \rightleftharpoons \mathrm{AMPH}^{+}
$$






FIgURE 1: Molecular structure of ampicillin.

To determine the most favorable protonation site, protonation affinity (PA) and basicity $(B)$ parameters were calculated via the following formula [21]:

$$
\begin{aligned}
\mathrm{PA} & =-\Delta H=-\left[H\left(\mathrm{AMPH}^{+}\right)-\left(H(\mathrm{AMP})+H\left(\mathrm{H}^{+}\right)\right)\right], \\
B & =-\Delta G=-\left[G\left(\mathrm{AMPH}^{+}\right)-\left(G(\mathrm{AMP})+G\left(\mathrm{H}^{+}\right)\right)\right],
\end{aligned}
$$

where $H$ and $G$ are the enthalpies and Gibbs free energy of neutral form (AMP), protonated form $\left(\mathrm{AMPH}^{+}\right)$, and proton $\left(\mathrm{H}^{+}\right) . H$ and $G$ of the proton at $298 \mathrm{~K}$ were taken from the literature $[21,22]$.

Adsorption centers of AMP are analyzed via the highest occupied molecular orbital (HOMO) and the lowest unoccupied molecular orbital (LUMO). Energy gap $\left(\Delta E_{L-H}\right)$ is estimated based on the following equation:

$$
\Delta E_{L-H}=E_{\text {LUMO }}-E_{\mathrm{HOMO}} .
$$

The local reactivity for nucleophilic $\left(f^{+}\right)$and electrophilic $(f)$ attacks was measured by Fukui functions [23]. These indexes were visualized by Multiwfn software [24-26].

\subsubsection{Monte Carlo and Molecular Dynamics Simulations.} The simulation methods were performed by Material Studio 7.0. The Fe(110) surface with a thickness of $5 \AA$ was relaxed by using the smart minimizer method, and then it was enlarged to a $(10 \times 10)$ supercell. First, MC simulations have been performed in the adsorption locator tool using COMPASS with an energy convergence tolerance of $2 \times 10^{-5} \mathrm{kcal} / \mathrm{mol}$ and force convergence tolerance of $0.001 \mathrm{kcal} / \mathrm{mol} / \AA$. The proportion of water molecules to hydrogen chloride corresponding to $1 \mathrm{M} \mathrm{HCl}$ solution was $500 / 9$ [27]. The system $\left(24.82 \times 24.82 \times 26.09 \AA^{3}\right)$ containing $491 \mathrm{H}_{2} \mathrm{O}, 9 \mathrm{H}_{3} \mathrm{O}^{+}, 9 \mathrm{Cl}^{-}$, and 1 inhibitor molecule was constructed using the amorphous cell program. Finally, the corrosion system was built by placing the amorphous cell on $\mathrm{Fe}(110)$ supercell using the layer builder tool. Afterwards, MD simulations were executed in a simulation box $\left(24.82 \times 24.82 \times 37.71 \AA^{3}\right)$. The COMPASS force field was applied for the simulation of all AMP species and the whole system. The parameters set up for the MD simulation such as the temperature of $298 \mathrm{~K}$, the time step of the canonical ensemble (NVT) of $1.0 \mathrm{fs}$, and simulation time of $500 \mathrm{ps}$. The interaction energy ( $\left.E_{\text {interaction }}\right)$ and binding energies ( $\left.E_{\text {binding }}\right)$ between the studied molecule and the $\mathrm{Fe}(110)$ surface were computed using the following equations:

$$
\begin{aligned}
E_{\text {interaction }} & =E_{\text {total }}-\left(E_{\text {surface+solution }}+E_{\text {inhibitor }}\right), \\
E_{\text {binding }} & =-E_{\text {interaction }},
\end{aligned}
$$

where $E_{\text {total }}, E_{\text {surface+solution }}$ and $E_{\text {inhibitor }}$ denote the overall energy of the entire system, the energy of $\mathrm{Fe}(110)$ surface and solution without the inhibitor, and energy of inhibitor, respectively.

\section{Results and Discussion}

\subsection{Experimental Results}

3.1.1. Polarization Measurements. The results obtained from polarization experiments for mild steel with AMP's various concentrations in $\mathrm{HCl}$ media are shown in Figure 2. It is clear that the polarization plots have tended to shift to lower corrosion current density regions when AMP concentration changes from 0 to $100 \mathrm{ppm}$. Depending on the $E_{\text {corr }}$ shift, there are three common types of inhibitors such as cathodic, anodic, and mixed type. According to the literature reviews $[28,29]$, the inhibitor belongs to a mixed class if $E_{\text {corr }}$ (inhibitor) is lower than $85 \mathrm{mV}$ compared with $E_{\text {corr }}$ (blank). As can be seen in Figure 1, the shift of $E_{\text {corr }}$ (AMP) displacement is not remarkable; thus, AMP is regarded as a type of mixed inhibitor.

Electrochemical corrosion factors recorded from the polarization measurements include corrosion potential $\left(E_{\text {corr }}\right)$, corrosion current density $\left(I_{\text {corr }}\right)$, and cathodic and anodic Tafel slopes $\left(\beta_{c}\right.$ and $\left.\beta_{a}\right)$ (displayed in Table 1). Furthermore, it can be observed from Table 1 that the values of $\beta_{a}$ and $\beta_{c}$ change significantly in the presence of the inhibitor. It indicates that AMP inhibits the anodic and cathodic reactions. It means that AMP interacts with the iron surface to form the film that can prevent the corrosion process occurring at the anodic electrode (mild steel) and make slowly the $\mathrm{H}^{+}$ion reduction at the cathodic electrode.

The results of Figure 2 and Table 1 show that the inhibition efficiency (\%IE) of AMP goes up when increasing concentration and reaches maximum behavior of $84.9 \%$ at 100 ppm.

3.1.2. Electrochemical Impedance Spectroscopy (EIS). EIS is a helpful tool to provide more information about the anticorrosion activity of studied compounds on steel surfaces in an acidic environment. EIS of specimens with the absence/ presence of AMP is depicted in Nyquist diagrams (Figure 3). These diagrams display that when increasing the AMP concentrations, the Nyquist diameters significantly increase as compared with the blank sample and there are nearly no changes in the semicircular shapes. It means that the anticorrosion behavior of AMP on the iron surface is remarkable in an acidic environment.

As can be seen in Figure 3, all curves show a typical Nyquist diagram with single semicircles shifted along the real impedance of the horizontal axis. This indicates that 


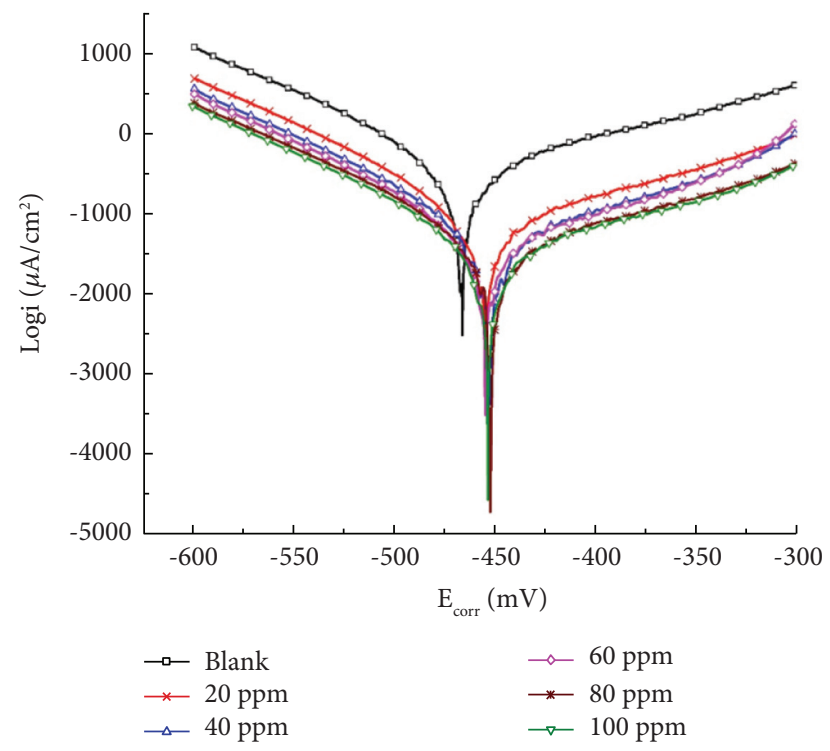

Figure 2: Polarization plots for mild steel electrode with AMP's different concentrations in acidic medium (1M HCl).

TABLE 1: Corrosion descriptors obtained from the polarization test at $298 \mathrm{~K}$.

\begin{tabular}{lcccc}
\hline Concentration $(\mathrm{ppm})$ & $-E_{\text {corr }}(\mathrm{mV} / \mathrm{SCE})$ & $-\beta_{c}(\mathrm{mV} / \mathrm{dec})$ & $\beta_{a}(\mathrm{mV} / \mathrm{dec})$ & $I_{\text {corr }}\left(\mu \mathrm{A} / \mathrm{cm}^{2}\right)$ \\
\hline 0.0 & 467.0 & 44.0 & 58.9 & 127.2 \\
20.0 & 456.6 & 32.1 & 49.4 & 25.4 \\
40.0 & 451.1 & 38.0 & 40.1 & 22.1 \\
60.0 & 455.5 & 32.6 & 44.3 & 21.2 \\
80.0 & 450.2 & 37.7 & 44.7 & 80.0 \\
100.0 & 454.3 & 30.9 & 47.0 & 83.6 \\
\hline
\end{tabular}

double-layer behavior and the charge transfer of the corrosion process primarily control the corrosion of low carbon steel.

For better visualization of the inflection points of the impedance module as well as the phase angle variation, Bode and phase angle plots are also analyzed and depicted in Figure 4 . The value of the phase angle increases significantly as the inhibitor concentration increases. It is worth noting that the phase angle values of the blank and the inhibitor samples are always lower than $-90^{\circ}$, which proves that the capacitor is nonideal.

To analyze the experimental results, an appropriate equivalent circuit model is required to correctly fit the impedance curves. The good fitted data are generally explained using the equivalent circuit shown in Figure 5, where $R_{\mathrm{s}}$ is the solution resistance, $R_{\mathrm{ct}}$ is the charge transfer resistance, CPE is the constant phase element, $L$ is the inductance, and $R_{L}$ is the inductive resistance. All relevant impedance parameters are calculated, and the results are given in Table 2. In order to observe better fit, the CPE element has been substituted for the capacitor. The impedance of the CPE can be given by the following equation [30-32]:

$$
Z_{\mathrm{CPE}}=\left[Y_{o} \cdot(j \omega)^{n}\right]^{-1}
$$

where $Y_{o}$ is the CPE constant, $j$ is the imaginary unit, $\omega$ is the angular frequency (given by $\omega=2 \pi f$ ), and $n$ is the CPE exponent. If the electrode surface is homogeneous and plane, $n$ is equal to 1 and the electrode surface can be treated as an ideal capacitance. The double-layer capacitance $\left(C_{\mathrm{dl}}\right)$ can be simulated via CPE using the following equation [31]:

$$
C_{\mathrm{dl}}=Y_{o} \cdot\left(\omega_{\max }\right)^{n-1} \text {. }
$$

The data obtained from Table 2 show that the resistance significantly changes with the increase of AMP concentration. Specifically, $R_{\mathrm{ct}}$ value of the blank sample is $11.91 \Omega \cdot \mathrm{cm}^{2}$ in $\mathrm{HCl}$. In the presence of AMP with concentrations from $20 \mathrm{ppm}$ to $100 \mathrm{ppm}, R_{\mathrm{ct}}$ values change from 77.54 to $129.70 \Omega \cdot \mathrm{cm}^{2}$. This loses control of electrical transfer, thereby reducing corrosion in hydrochloric acid. The possibility of anticorrosion increases gradually according to the AMP concentration.

When increasing AMP concentration, the $C_{\mathrm{dl}}$ value tends to decrease. Conforming to the Helmholtz model, the change of the $C_{\mathrm{dl}}$ value can make a valuable substitution of water molecules by the AMP molecules onto the iron surface, reducing the local dielectric constant or enhancing the double electrical layer thickness $[32,33]$. The decrease of $C_{\mathrm{dl}}$ may be caused by the adsorption of AMP taking place on the surface of the steel sample [34]. 


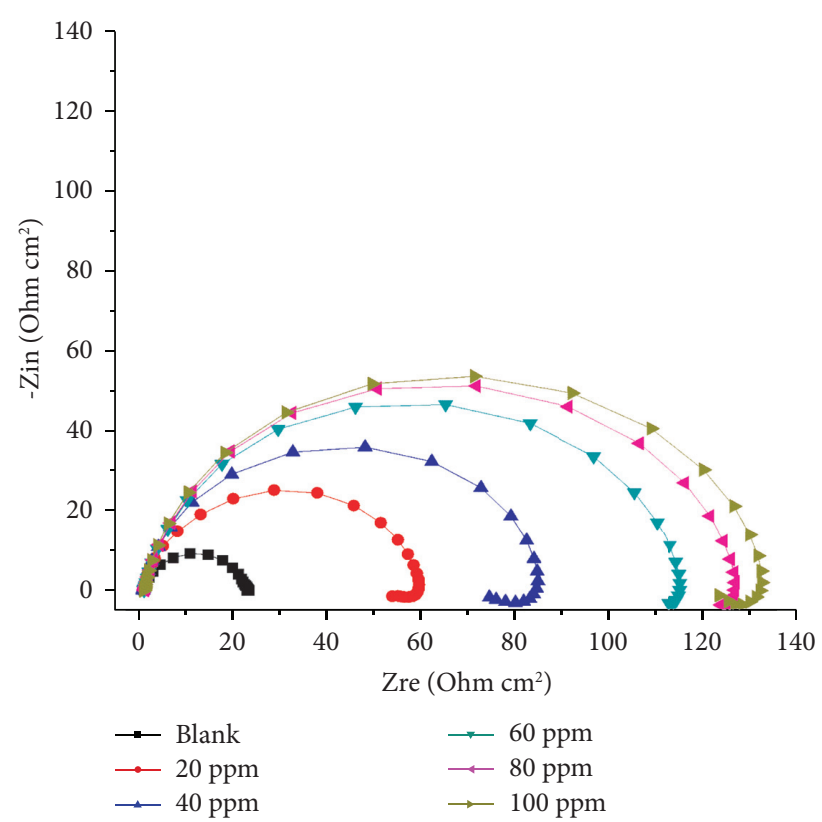

FIgURE 3: Nyquist diagrams of mild steel in corrosive media at $298 \mathrm{~K}$ with AMP's various concentrations.

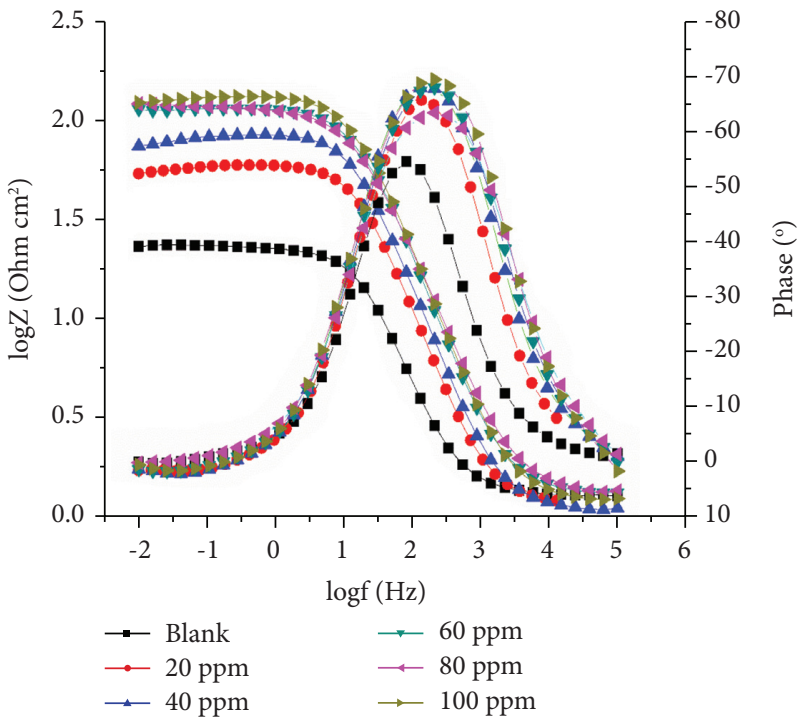

Figure 4: Bode magnitude plot and phase angle plot for the corrosion of mild steel in $1 \mathrm{M} \mathrm{HCl}$ in the absence and presence of various concentrations of AMP.

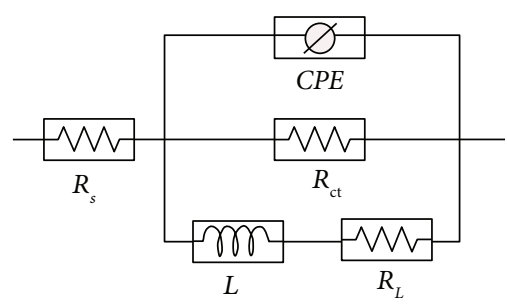

FIGURE 5: Equivalent circuit model proposed to match the EIS data.

In addition, when AMP is added into acidic solution, the $n$-value decreases, which indicates that the electrode surface becomes less homogeneous, relating to the existence of an adsorbent layer formed on the steel surface [35].
Besides, the corrosion inhibition behavior increased from $83.4 \%$ to $90.1 \%$ when the AMP concentration increased from $20 \mathrm{ppm}$ to $100 \mathrm{ppm}$. It reveals that an adsorbent layer may form on the steel surface to protect the electrode 
TABLE 2: Electrochemical impedance factors for mild steel with the concentration range of AMP from 0 to $100 \mathrm{ppm}$ in $1 \mathrm{M} \mathrm{HCl}$.

\begin{tabular}{|c|c|c|c|c|c|c|c|c|c|c|}
\hline $\begin{array}{l}\text { Conc. of inhibitor } \\
(\mathrm{ppm})\end{array}$ & $\begin{array}{c}R_{s} \\
\left(\Omega \cdot \mathrm{cm}^{2}\right)\end{array}$ & $\begin{array}{c}R_{\mathrm{ct}} \\
\left(\Omega \cdot \mathrm{cm}^{2}\right)\end{array}$ & $\begin{array}{c}\mathrm{CPE} \\
\left(\mu \Omega^{-1} \cdot \mathrm{cm}^{-2}\right)\end{array}$ & $\begin{array}{c}L \\
(\mathrm{kH})\end{array}$ & $\begin{array}{c}R_{L} \\
\left(\Omega \cdot \mathrm{cm}^{2}\right)\end{array}$ & $\begin{array}{c}R_{p} \\
\left(\Omega \cdot \mathrm{cm}^{2}\right)\end{array}$ & $n$ & $\begin{array}{l}f_{\max } \\
(\mathrm{Hz})\end{array}$ & $\begin{array}{c}C_{\mathrm{dl}} \\
\left(\mu \mathrm{F} \cdot \mathrm{cm}^{-2}\right)\end{array}$ & IE (\%) \\
\hline Blank & 1.095 & 11.91 & 267.20 & 18.80 & 3.54 & 13.00 & 0.879 & 19.68 & 149.17 & - \\
\hline 20 & 1.088 & 77.54 & 112.00 & 19.59 & 11.88 & 78.32 & 0.897 & 17.13 & 69.17 & 83.41 \\
\hline 40 & 1.100 & 87.57 & 85.29 & 21.44 & 3.98 & 88.31 & 0.896 & 12.25 & 54.29 & 85.28 \\
\hline 60 & 1.230 & 100.90 & 58.07 & 35.82 & 4.27 & 101.85 & 0.884 & 12.25 & 35.09 & 87.24 \\
\hline 80 & 1.326 & 115.40 & 48.23 & 64.00 & 3.90 & 116.52 & 0.831 & 12.25 & 23.15 & 88.85 \\
\hline 100 & 1.233 & 129.70 & 34.63 & 76.02 & 2.21 & 130.71 & 0.819 & 12.25 & 15.78 & 90.06 \\
\hline
\end{tabular}

corrosion [35]. Based on data in Figure 3 and Table 2, the results of the impedance spectroscopy are in the same trend with data of the polarization curves.

3.1.3. Surface Analysis. Surface analysis can be interpreted based on the iron surface images in an acidic environment without/with the presence of the AMP inhibitor. Figure 6 displays SEM images of the specimen with AMP's optimal concentration before and after treating in $1 \mathrm{M} \mathrm{HCl}$ solution. The surface of the specimen is very rough with several pits and cavities in $1 \mathrm{M} \mathrm{HCl}$ because of acid attack (see Figure 6(b)). On the contrary, with the presence of AMP, the micrograph surface of iron becomes smoother and more homogeneous (see Figure 6(c)). This can be explained by an inhibiting film layer was formed by the AMP molecule adsorption on the iron surface, preventing the dissolution of mild steel electrode. This result also affirms the inhibition ability of AMP on mild steel corrosion.

\subsection{Computational Study}

3.2.1. Quantum Chemical Calculation. The structural characteristics of the inhibitors were studied by using computational chemistry approaches to further explain the pathway of inhibition. In acidic environment, heteroatoms (such as $\mathrm{O}, \mathrm{N}$, and $\mathrm{S}$ ) in the corrosion inhibitor molecule can be easily protonated $[21,36]$. Hence, to mimic the experimental conditions, both existed states of AMP were investigated. AMP has seven possible sites for protonation which are $\mathrm{O} 19, \mathrm{O} 20, \mathrm{O} 24, \mathrm{~N} 9, \mathrm{~N} 12, \mathrm{~N} 18$, and S14 (Cartesian coordinates of all optimized structures are shown in Table S1). To find the most likely protonation position of AMP, proton affinity and basicity values were evaluated by following the B3LYP/6-31+G(d,p) method, and the obtained results are shown in Table 3 . It is found show that the priorly probable position for protonation is $\mathrm{N} 18$ with $\mathrm{PA}=227.4 \mathrm{kcal} / \mathrm{mol}$ and $\mathrm{GB}=235.2 \mathrm{kcal} / \mathrm{mol}$. For further explanation, optimized geometry structures, frontier molecular orbitals, and essential quantum chemical factors for both existed forms of AMP are discussed in detail.

The effect of the corrosion protection process depends on the adsorptive activity of an inhibitor on the metal surface, which was explained by the electron donor-acceptor ability between the organic compound and iron atom. HOMO electron distribution characterizes the electron donor ability, while LUMO electron distribution represents the acceptor ability. The optimized structures, HOMOs, and
LUMOs of AMP inhibitor following neutral and protonated states are depicted in Figure 7.

Regarding the neutral form, the HOMO finds a major contribution from the benzene ring and the amino $\left(-\mathrm{NH}_{2}\right)$ group, while the LUMO contributed around the ring containing sulfur atom and carboxylic $(-\mathrm{COOH})$ group. For the protonated form, the electron density region allocated around two heterocycles containing nitrogen and sulfur atoms is denoted by HOMO, while the electron density of LUMO shows the main contribution from the aromatic ring and the amino group. It can be seen that the delocalized electron density of frontier molecular orbital of protonated AMP is reversed to that of neutral ones. Accordingly, these areas are almost active in the transfer of electrons between the metal surface and APM or vice versa. The frontier molecular orbital density distributions were useful in adsorptive orientation between the metal surface and AMP [37]. Moreover, the dominant solvent models [38-40] for both neutral and cationic forms are also shown in Figure S1.

To indicate the strength of donor-acceptor interactions between the surface of the iron and APM, the energies of $E_{\mathrm{HOMO}}, E_{\mathrm{LUMO}}$, and $\Delta E_{L-H}$ (energy gap) were calculated. These main parameters define the reactivity of an inhibitor molecule. If the $E_{\mathrm{HOMO}}$ value is higher, the electron donating ability will be easier, whereas if the $E_{\text {LUMO }}$ value is lower, the electron accepting ability is more preferred. The obtained results in Figure 7 indicate that the $E_{\text {HOMO values of the }}$ neutral state $(-6.636 \mathrm{eV}$ and $-6.794 \mathrm{eV})$ are higher than those of protonated state $(-9.497 \mathrm{eV}$ and $-7.001 \mathrm{eV})$ in the gas phase and solvent, respectively. Hence, the neutral form tends to transfer electrons to the vacant $3 \mathrm{~d}$-orbitals of iron and forms an adsorptive layer on the surface of mild steel. However, the $E_{\text {LUMO }}$ values of the protonated types in the gas phase and water $(-4.705 \mathrm{eV}$ and $-1.356 \mathrm{eV}$, respectively) are lower than those of the neutral types $(-1.042 \mathrm{eV}$ and $-1.016 \mathrm{eV}$, respectively). It means that the protonated state is easy to gain the electrons from the d-orbital of the metal compared with the neutral state. In addition, the energy gap $\left(\Delta E_{L-H}\right)$ also informs about the reactivity or stability of the inhibitor molecule. It is an essential descriptor that characterizes the binding ability of inhibitor molecules to the metal surface. With a lower $\Delta E_{L-H}$ value, a molecule shows greater reactivity, leading to an increase of adsorption onto an iron surface $[41,42]$. Figure 8 visualizes the density of states (DOS) spectra in the gas phase and water for both existed forms of AMP. The green lines are the occupied orbitals. The red lines are the unoccupied orbitals. Also, the gap between them is the band gap. Based on data from 


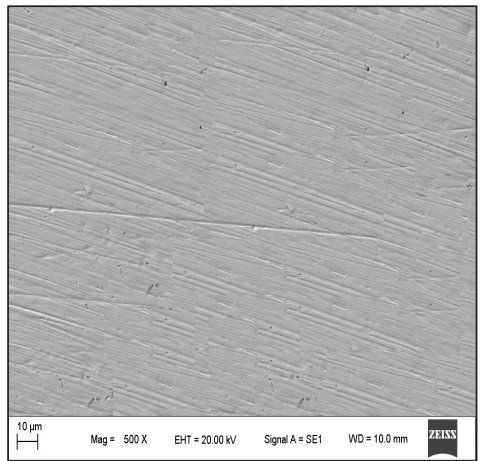

(a)

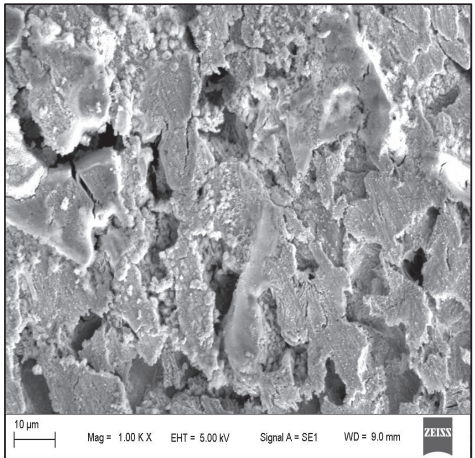

(b)

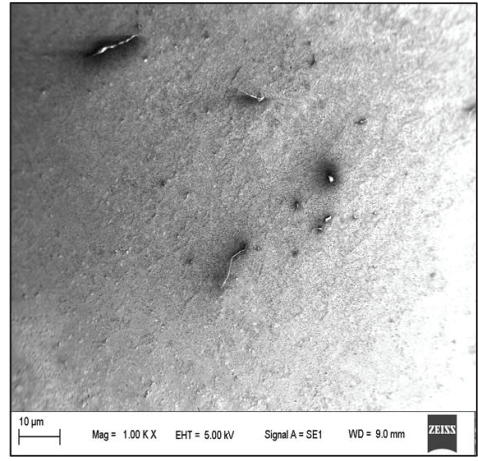

(c)

FIGURE 6: SEM images of original mild steel surface (a) immersed in $1 \mathrm{M} \mathrm{HCl}$ solution containing different AMP concentrations: 0 ppm (b) and $100 \mathrm{ppm}(\mathrm{c})$.

TABle 3: Proton affinity (PA) and gas basicity (GB) values were carried out by using the B3LYP/6-31+G(d, p) method.

\begin{tabular}{lccccrr}
\hline $\begin{array}{l}\text { Compound } \\
\text { Protonation site }\end{array}$ & N9 & N12 & N18 & OMP & O20 & O24 \\
\hline PA (kcal/mol) & 203.3 & 213.1 & $\mathbf{2 2 7 . 4}$ & 225.3 & 205.0 & 198.6 \\
GB (kcal/mol) & 211.5 & 221.1 & $\mathbf{2 3 5 . 2}$ & 233.2 & 212.4 & 206.1 \\
$\Delta$ PA $^{*}$ & -24.1 & -14.3 & $\mathbf{0 . 0}$ & -2.1 & -22.4 & -28.8 \\
$\Delta$ GB $^{* *}$ & -23.7 & -14.1 & $\mathbf{0 . 0}$ & -2.0 & -22.8 & -29.1 \\
\hline
\end{tabular}

${ }^{*} \Delta \mathrm{PA}=\mathrm{PA}$ (less stable) $-\mathrm{PA}$ (most stable). ${ }^{* *} \Delta \mathrm{GB}=\mathrm{GB}$ (less stable) $-\mathrm{GB}$ (most stable).

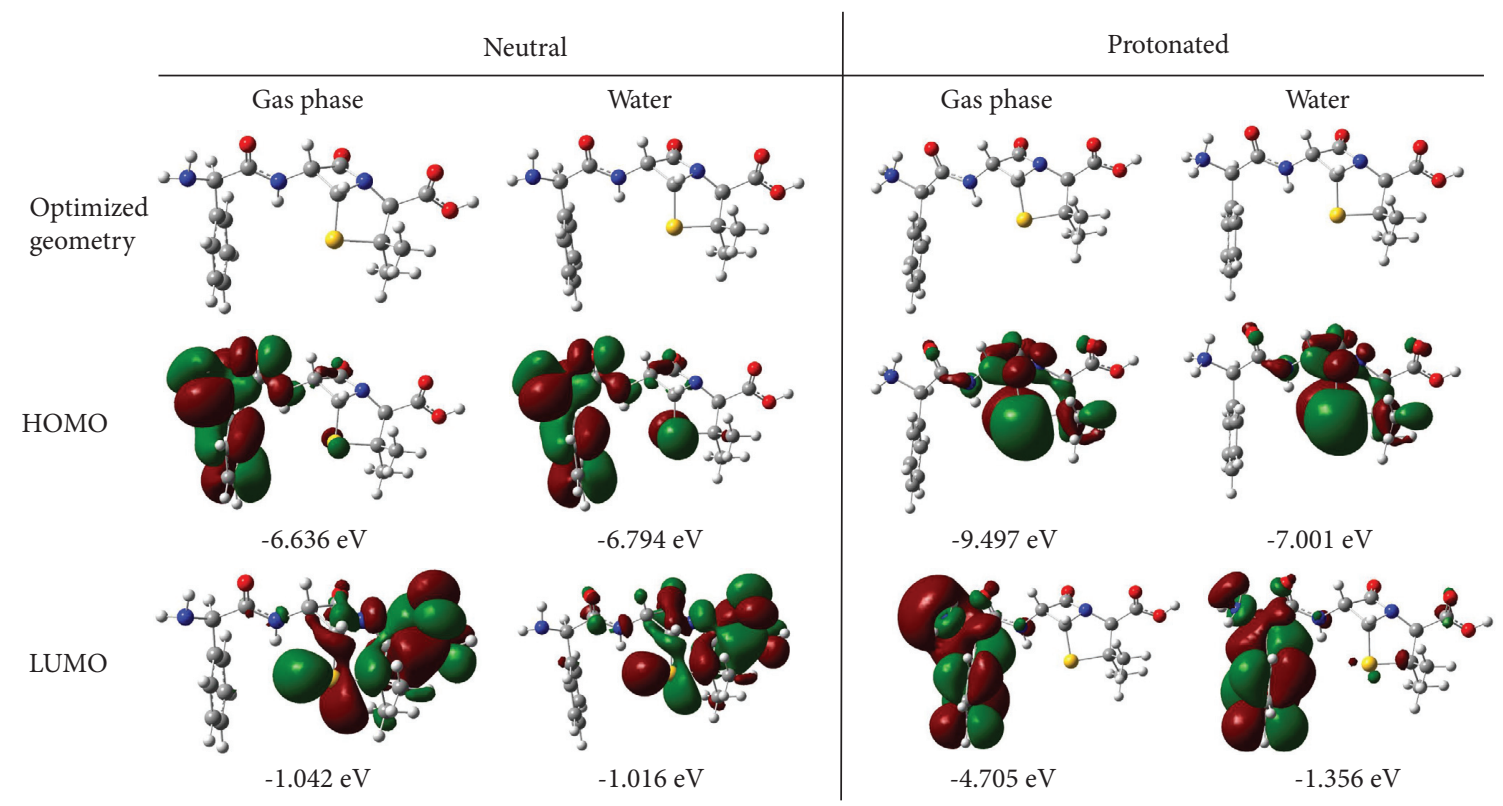

FIGURE 7: Optimized molecular geometry and frontier molecular orbitals (HOMO and LUMO) of AMP inhibitor following both neutral and protonated states.

Figure 8 , the $\Delta E_{L-H}$ value of the protonated species is $0.802 \mathrm{eV}$ and $0.132 \mathrm{eV}$ lower than that of the neutral forms corresponding to the gas phase and water. Hence, the protonated forms of AMP are more expected to adsorb on the metal surface.

The nucleophilic/electrophilic sites (susceptible atoms and regions) in the molecular structures of AMP were localized by the Fukui function $f^{+}$and $f^{-}$. Figure 9 displays the electron density surfaces of $f^{+}$and $f^{-}$for two states of AMP. The areas of the molecules which have higher values of $f^{+}$are more sensitive to be attacked by electron abundant groups. On the contrary, the positions of the molecules which have higher values of $f^{-}$are interacted easily with electron poor groups. As can be shown in Figure 9, the site of 

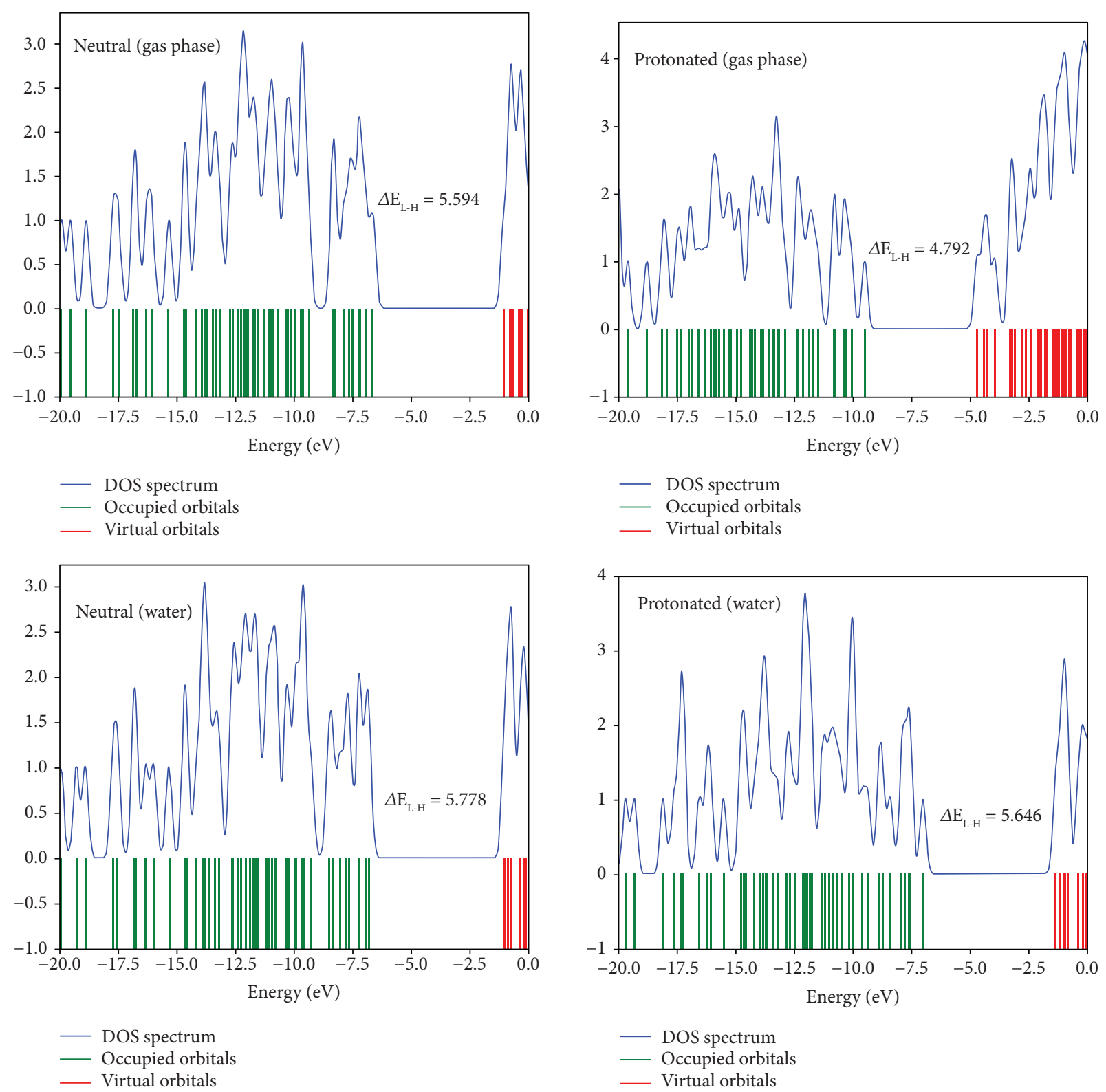

FIgURE 8: The density of states (DOS) spectra for both existed forms of AMP in the gas phase and water.

the sulfur atom, the amino group, and the carboxyl group is most likely as electrophilic centers, which cannot interact with negatively charged steel, while the function $f^{-}$distributes almost over phenyl ring that donates electrons to surface Fe atoms. Otherwise, the electron density surfaces for $f^{+}$and $f^{-}$of the protonated AMP are different from those of neutral species.

3.2.2. Molecular Simulations. MC and MD simulations were considered as useful theoretical tools to analyze the interaction between adsorbent and $\mathrm{Fe}(110)$ surface at a molecular level. The lowest energy configurations of neutral (AMP) and protonated $\left(\mathrm{AMPH}^{+}\right)$forms on $\mathrm{Fe}(110)$ obtained from the MC simulation are presented in Figure 10. It is clear that the molecular skeleton of neutral/protonated AMP is nearly parallel to the plane of the metal surface. The adsorption energy is more negative, and the studied system is more stable with strong interaction between the inhibitor and iron surface. As can be seen from Table 4, the obtained results indicate that the protonated form has a greater ability to interact with the metallic surface and adsorbs more strongly compared to the neutral form because the adsorption energy of $\mathrm{AMPH}^{+}(-196.15 \mathrm{kcal} / \mathrm{mol})$ is more negative than that of $\operatorname{AMP}(-181.24 \mathrm{kcal} / \mathrm{mol})$.

To imitate the real corrosive environment, $\mathrm{MD}$ simulations were carried out in a box which consisted of $491 \mathrm{H}_{2} \mathrm{O}$, $9 \mathrm{H}_{3} \mathrm{O}^{+}$, and $9 \mathrm{Cl}^{-}$corresponding to $1 \mathrm{M} \mathrm{HCl}$ solution to further examine the anticorrosion activity of AMP. From the most stable adsorption configurations of both neutral and protonated AMP on $\mathrm{Fe}(110) / \mathrm{HCl}$ system (Figure 11), it can be seen that all the visualized configurations have a tendency 


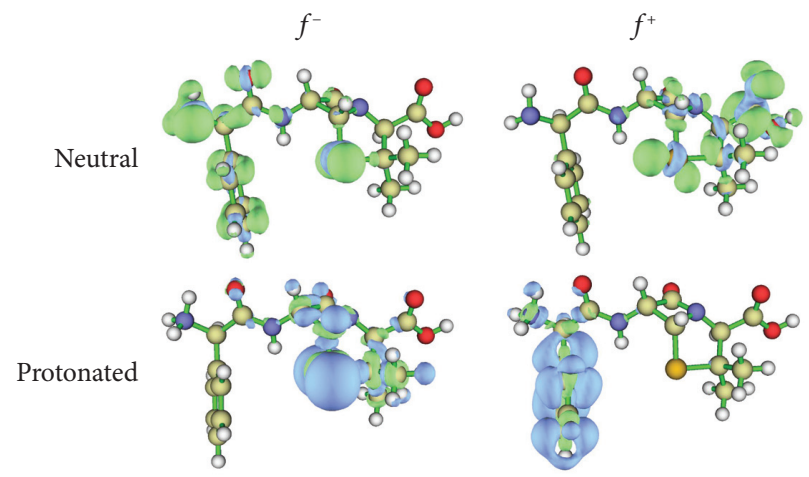

FIGURE 9: Fukui indices for the electrophilic $\left(f^{+}\right)$and nucleophilic $\left(f^{-}\right)$sites for two states of AMP visualized at 0.002 isosurfaces.

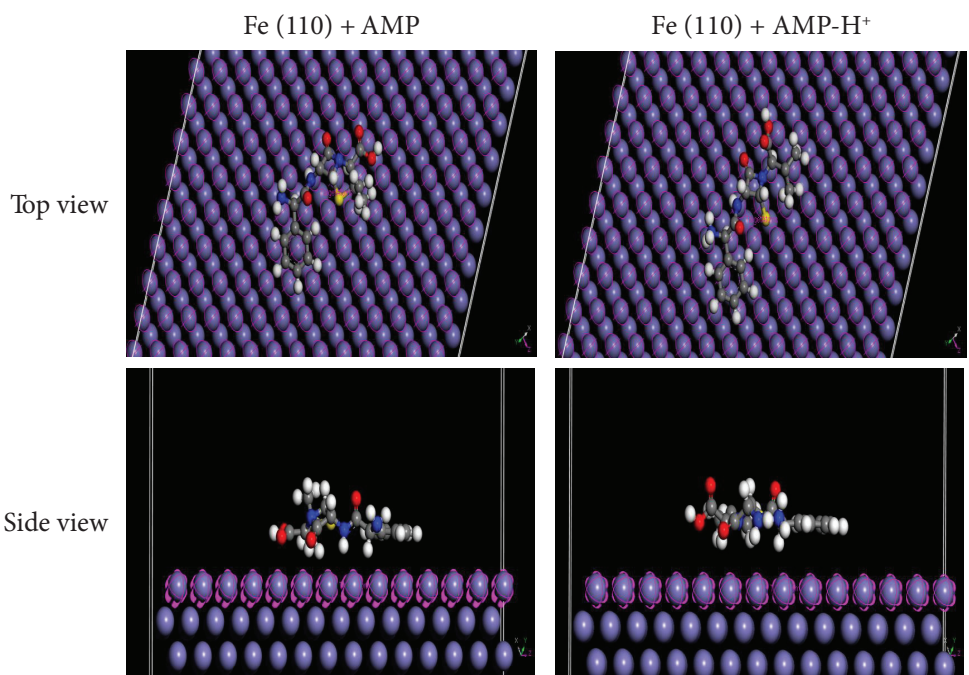

Figure 10: Top and side views of AMP and $\mathrm{AMPH}^{+}$on $\mathrm{Fe}(110)$ surface.

TABLE 4: The adsorption energies for $\mathrm{AMP}$ and $\mathrm{AMPH}^{+}$on $\mathrm{Fe}(110)$ surface obtained from the MC simulation.

to orient parallel to the iron surface in $\mathrm{HCl}$ solution. This is similar to the obtained results from MC simulations. It proves that the heteroatoms and $\pi$-electrons in the states of AMP (neutral and protonated) can interact strongly with vacant $\mathrm{d}$-orbitals of $\mathrm{Fe}$ to form the stable coordination bonds. Then, the thin film layer can be formed covering the steel surface to protect the corrosion process. Furthermore, the interactions between the inhibitor and the steel surface were quantitatively studied by the interaction energy $\left(E_{\mathrm{In}-}\right.$ teraction $)$ and binding energy $\left(E_{\text {Binding }}\right)$, which are the key components to determine the binding ability of AMP onto the iron surface. According to data from Table 5, the $E_{\text {In- }}$ teraction value of $\mathrm{Fe}(110) / \mathrm{AMPH}^{+} / \mathrm{HCl}$ system is more negative than that of $\mathrm{Fe}(110) / \mathrm{AMP} / \mathrm{HCl}$ system. It indicates that the adsorption in the $\mathrm{Fe}(110) / \mathrm{AMPH}^{+} / \mathrm{HCl}$ system is more stable and stronger leading to the higher corrosion inhibitor efficiency than $\mathrm{Fe}(110) / \mathrm{AMP} / \mathrm{HCl}$ system. Thus, the protonated form of AMP has significantly contributed to the protection of Fe surface against the corrosive process.

3.3. Proposed Mechanism of Adsorption and Inhibition. Based on the data obtained from the experimental and theoretical investigations, the suggested mechanism for the adsorption and inhibition of neutral/protonated AMP in $1 \mathrm{M}$ $\mathrm{HCl}$ solution is displayed in Figure 12. As per Figure 12, the adsorption process of AMP on the iron surface can occur by the electrostatic interaction, the interaction of lone electron pairs, $\pi$-electron, and vacant $d$-orbital of surface iron atoms. In the acid environment, AMP is protonated to become cationic species and the electrostatic interaction may occur with chloride ions $\left(\mathrm{Cl}^{-}\right)$which gets absorbed in the positively 

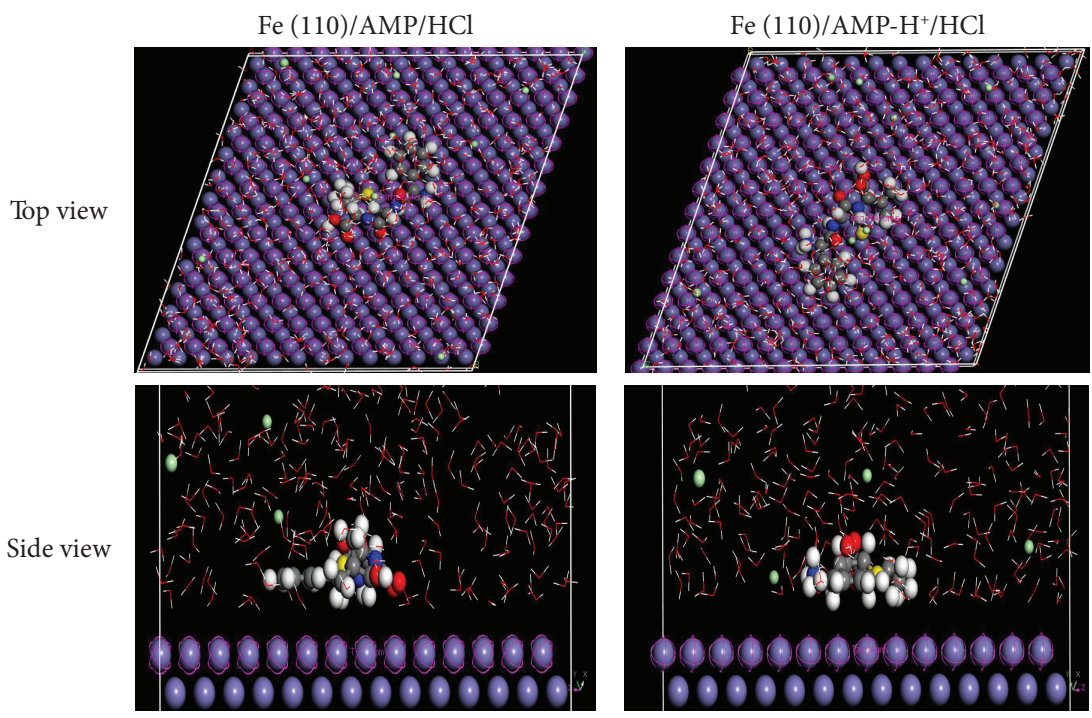

FIgURE 11: Top and side views for the interaction between neutral/protonated APM and surface mild steel in $1 \mathrm{M} \mathrm{HCl}$ solution.

TABLE 5: Interaction and binding energies of $\mathrm{AMP}$ and $\mathrm{AMPH}^{+}$on $\mathrm{Fe}(110)$ surface at $298 \mathrm{~K}$.

\begin{tabular}{lcc}
\hline System & $E_{\text {Interaction }}(\mathrm{kcal} / \mathrm{mol})$ & $E_{\text {Binding }}(\mathrm{kcal} / \mathrm{mol})$ \\
\hline $\mathrm{Fe}(110) / \mathrm{AMP} / \mathrm{HCl}$ & -51.01 & 51.01 \\
$\mathrm{Fe}(110) / \mathrm{AMPH}^{+} / \mathrm{HCl}$ & -54.94 & 54.94 \\
\hline
\end{tabular}

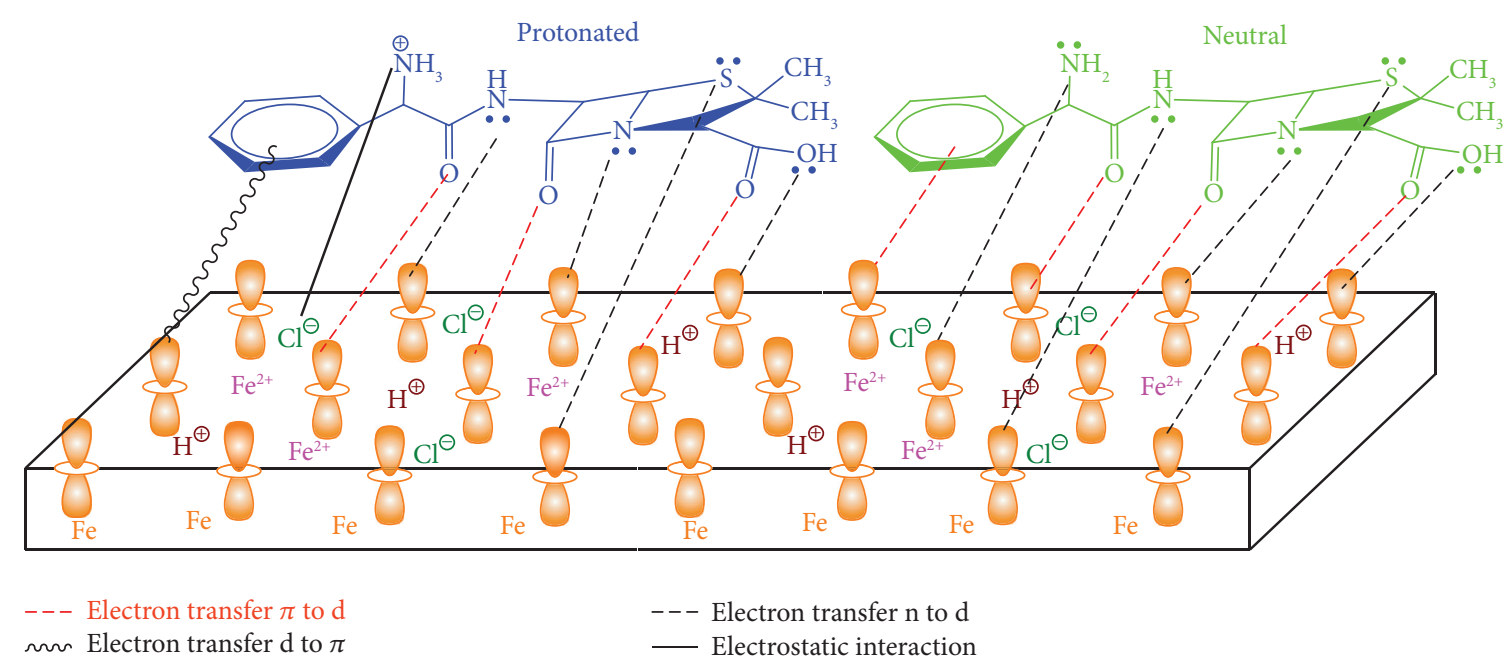

FIGURE 12: Schematic mechanism suggested for the adsorption of neutral/protonated AMP on the surface of mild steel in $1 \mathrm{M} \mathrm{HCl}$ environment.

charged iron surface $\left(\mathrm{Fe}^{2+}\right)$. It can lead to forming a film layer of protective complex (FeClAMPH+). Moreover, the neutral form of AMP may exist in acidic solutions. Expectedly, the neutral AMP may get adsorbed on the mild steel surface by sharing electrons between heteroatoms $(\mathrm{O}$, $\mathrm{N}$, and $\mathrm{S}$ ), $\pi$-electron, and vacant d-orbital of iron atoms.

\section{Conclusions}

In this context, the anticorrosion mechanism of AMP on mild steel in $\mathrm{HCl} 1 \mathrm{M}$ acid medium was explored using both experimental and theoretical approaches. Some results obtained from this paper can be highlighted as follows:

(i) Experimental techniques (including electrochemical measurements and electrochemical impedance spectroscopy) demonstrate that AMP has potential inhibitive characteristics for the corrosion of mild steel in $1 \mathrm{M} \mathrm{HCl}$ acid. The corrosion inhibition behavior of AMP increases following the concentration range of 0 ppm-100 ppm and reaches maximum efficiency at $100 \mathrm{ppm}$. 
(ii) SEM images also indicated that the iron surface was covered with the adsorbed protective molecules of AMP.

(iii) To further explain the anticorrosion properties in the real environment, both neutral/protonated states $\left(\mathrm{AMP} / \mathrm{AMPH}^{+}\right)$were studied in detail through quantum chemical calculations, Monte Carlo simulation, and molecular dynamics simulations. It can be noted that $\mathrm{AMPH}^{+}$has significantly contributed to protecting the mild steel surfaces against the corrosive process.

\section{Data Availability}

No data were used to support this study.

\section{Conflicts of Interest}

The authors declare that they have no conflicts of interest.

\section{Acknowledgments}

This research was funded by the Vietnam National Foundation for Science and Technology Development (NAFOSTED) under grant number 104.06-2020.17 (P.C.N).

\section{Supplementary Materials}

Table S1: optimized structure of neutral and protonated ampicillin in gas phase at the B3LYP/6-31+G(d,p) level. Figure S1: optimized structure, highest occupied molecular orbital (HOMO), and lowest unoccupied molecular orbital (LUMO) for both neutral (AMP) and protonated (AMPH+) forms under dominant solvent model. (Supplementary Materials)

\section{References}

[1] P. B. Raja and M. G. Sethuraman, "Natural products as corrosion inhibitor for metals in corrosive media-a review," Materials Letters, vol. 62, no. 1, pp. 113-116, 2008.

[2] G. Gece, "Drugs: a review of promising novel corrosion inhibitors," Corrosion Science, vol. 53, no. 12, pp. 3873-3898, 2011.

[3] B. Sanyal, "Organic compounds as corrosion inhibitors in different environments-a review," Progress in Organic Coatings, vol. 9, no. 2, pp. 165-236, 1981.

[4] S. A. Umoren and U. M. Eduok, "Application of carbohydrate polymers as corrosion inhibitors for metal substrates in different media: a review," Carbohydrate Polymers, vol. 140, pp. 314-341, 2016.

[5] D. de la Fuente, I. Díaz, J. Simancas, B. Chico, and M. Morcillo, "Long-term atmospheric corrosion of mild steel," Corrosion Science, vol. 53, no. 2, pp. 604-617, 2011.

[6] I. B. Obot, E. E. Ebenso, N. O. Obi-Egbedi, A. S. Afolabi, and Z. M. Gasem, "Experimental and theoretical investigations of adsorption characteristics of itraconazole as green corrosion inhibitor at a mild steel/hydrochloric acid interface," Research on Chemical Intermediates, vol. 38, no. 8, pp. 1761-1779, 2012.

[7] V. R. Saliyan and A. V. Adhikari, "Quinolin-5-ylmethylene-3$\{[8$-(trifluoromethyl)quinolin-4-yl]thio\}propanohydrazide as an effective inhibitor of mild steel corrosion in $\mathrm{HCl}$ solution," Corrosion Science, vol. 50, no. 1, pp. 55-61, 2008.

[8] N. O. Eddy, E. E. Ebenso, and U. J. Ibok, "Adsorption, synergistic inhibitive effect and quantum chemical studies of ampicillin (AMP) and halides for the corrosion of mild steel in $\mathrm{H}_{2} \mathrm{SO}_{4}$," Journal of Applied Electrochemistry, vol. 40, no. 2, pp. 445-456, 2009.

[9] K. Babic-Samardzija, C. Lupu, N. Hackerman, A. R. Barron, and A. Luttge, "Inhibitive properties and surface morphology of a group of heterocyclic diazoles as inhibitors for acidic iron corrosion," Langmuir: The ACS Journal of Surfaces and Colloids, vol. 21, no. 26, pp. 12187-12196, 2005.

[10] A. Ehsani, M. G. Mahjani, R. Moshrefi, H. Mostaanzadeh, and J. S. Shayeh, "Electrochemical and DFT study on the inhibition of 316L stainless steel corrosion in acidic medium by 1(4-nitrophenyl)-5-amino-1H-tetrazole," RSC Advances, vol. 4, no. 38, pp. 20031-20037, 2014.

[11] B. E. A. Rani and B. B. J. Basu, "Green inhibitors for corrosion protection of metals and alloys: an overview," International Journal of Corrosion, vol. 2012, Article ID 380217, 15 pages, 2012.

[12] G. Golestani, M. Shahidi, and D. Ghazanfari, "Electrochemical evaluation of antibacterial drugs as environmentfriendly inhibitors for corrosion of carbon steel in $\mathrm{HCl}$ solution," Applied Surface Science, vol. 308, pp. 347-362, 2014.

[13] M. Alfakeer, M. Abdallah, and A. Fawzy, "Corrosion inhibition effect of expired ampicillin and flucloxacillin drugs for mild steel in aqueous acidic medium," International Journal of Electrochemical Science, vol. 15, pp. 3283-3297, 2020.

[14] I. A. Adejoro, F. K. Ojo, and S. K. Obafemi, "Corrosion inhibition potentials of ampicillin for mild steel in hydrochloric acid solution," Journal of Taibah University for Science, vol. 9, no. 2, pp. 196-202, 2018.

[15] N. Islam and S. Kaya, Conceptual Density Functional Theory and Its Application in the Chemical Domain, CRC Press, Boca Raton, FL, USA, 2018.

[16] H. Ashassi-Sorkhabi, B. Shaabani, and D. Seifzadeh, "Effect of some pyrimidinic Shciff bases on the corrosion of mild steel in hydrochloric acid solution," Electrochimica Acta, vol. 50, no. 16-17, pp. 3446-3452, 2005.

[17] F. Bentiss, M. Lagrenee, M. Traisnel, and J. C. Hornez, "The corrosion inhibition of mild steel in acidic media by a new triazole derivative," Corrosion Science, vol. 41, no. 4, pp. 789-803, 1999.

[18] E. Cancès, B. Mennucci, and J. Tomasi, "A new integral equation formalism for the polarizable continuum model: theoretical background and applications to isotropic and anisotropic dielectrics," The Journal of Chemical Physics, vol. 107, no. 8, pp. 3032-3041, 1997.

[19] J. Tomasi, B. Mennucci, and E. Cancès, "The IEF version of the PCM solvation method: an overview of a new method addressed to study molecular solutes at the QM Ab initio level," Journal of Molecular Structure-Theochem, vol. 464, no. 1, pp. 211-226, 1999.

[20] M. J. Frisch, G. W. Trucks, H. B. Schlegel et al., Gaussian 09, Revision A.02, Gaussian, Inc., Wallingford, CT, USA, 2009.

[21] L. O. Olasunkanmi, I. B. Obot, M. M. Kabanda, and E. E. Ebenso, "Some quinoxalin-6-yl derivatives as corrosion inhibitors for mild steel in hydrochloric acid: experimental and theoretical studies," Journal of Physical Chemistry C, vol. 119, no. 28, pp. 16004-16019, 2015.

[22] E. Raczyńska, M. Makowski, E. Górnicka, and M. Darowska, "Ab initio studies on the preferred site of protonation in 
cytisine in the gas phase and water," International Journal of Molecular Sciences, vol. 6, no. 1, pp. 143-156, 2005.

[23] I. B. Obot, D. D. Macdonald, and Z. M. Gasem, "Density functional theory (DFT) as a powerful tool for designing new organic corrosion inhibitors. Part 1: an overview," Corrosion Science, vol. 99, pp. 1-30, 2015.

[24] W. Yang and W. J. Mortier, "The use of global and local molecular parameters for the analysis of the gas-phase basicity of amines," Journal of the American Chemical Society, vol. 108, no. 19, pp. 5708-5711, 1986.

[25] T. Lu and F. Chen, "Quantitative analysis of molecular surface based on improved marching tetrahedra algorithm," Journal of Molecular Graphics and Modelling, vol. 38, pp. 314-323, 2012.

[26] T. Lu and F. Chen, "Multiwfn: a multifunctional wavefunction analyzer," Journal of Computational Chemistry, vol. 33, no. 5, pp. 580-592, 2012.

[27] Z. Salarvand, M. Amirnasr, M. Talebian, K. Raeissi, and S. Meghdadi, "Enhanced corrosion resistance of mild steel in $1 \mathrm{M} \mathrm{HCl}$ solution by trace amount of 2-phenyl-benzothiazole derivatives: experimental, quantum chemical calculations and molecular dynamics (MD) simulation studies," Corrosion Science, vol. 114, pp. 133-145, 2017.

[28] E. S. Ferreira, C. Giacomelli, F. C. Giacomelli, and A. Spinelli, "Evaluation of the inhibitor effect of 1-ascorbic acid on the corrosion of mild steel," Materials Chemistry and Physics, vol. 83, no. 1, pp. 129-134, 2004.

[29] A. K. Satapathy, G. Gunasekaran, S. C. Sahoo, K. Amit, and P. V. Rodrigues, "Corrosion inhibition by Justicia gendarussa plant extract in hydrochloric acid solution," Corrosion Science, vol. 51, no. 12, pp. 2848-2856, 2009.

[30] H. Cang, W. Shi, J. Shao, and Q. Xu, "Study of Stevia rebaudiana leaves as green corrosion inhibitor for mild steel in sulphuric acid by electrochemical techniques," International Journal of Electrochemical Science, vol. 7, no. 4, pp. 3726-3736, 2012.

[31] S. K. Shukla, M. Quraishi, and E. E. Ebenso, "Adsorption and corrosion inhibition properties of cefadroxil on mild steel in hydrochloric acid," International Journal of Electrochemical Science, vol. 6, pp. 2912-2931, 2011.

[32] Z. Tao, W. He, S. Wang, S. Zhang, and G. Zhou, "Adsorption properties and inhibition of mild steel corrosion in $0.5 \mathrm{M}$ $\mathrm{H}_{2} \mathrm{SO}_{4}$ solution by some triazol compound," Journal of Materials Engineering and Performance, vol. 22, no. 3, pp. 774-781, 2013.

[33] R. Saratha, S. V. Priya, and P. Thilagavathy, "Investigation of Citrus aurantiifolia leaves extract as corrosion inhibitor for mild steel in 1M HCl," E-Journal of Chemistry, vol. 6, no. 3, pp. 785-795, 2009.

[34] A. Ostovari, S. M. Hoseinieh, M. Peikari, S. R. Shadizadeh, and S. J. Hashemi, "Corrosion inhibition of mild steel in $1 \mathrm{M} \mathrm{HCl}$ solution by henna extract: a comparative study of the inhibition by henna and its constituents (lawsone, gallic acid, $\alpha$-dglucose and tannic acid)," Corrosion Science, vol. 51, no. 9, pp. 1935-1949, 2009.

[35] M. Lebrini, F. Robert, P. Blandinieres, and C. Roos, "Corrosion inhibition by Isertia coccinea plant extract in hydrochloric acid solution," International Journal of Electrochemical Science, vol. 6, no. 7, pp. 2443-2460, 2011.

[36] M. Ramezanzadeh, G. Bahlakeh, Z. Sanaei, and B. Ramezanzadeh, "Studying the Urtica dioica leaves extract inhibition effect on the mild steel corrosion in $1 \mathrm{M} \mathrm{HCl}$ solution: complementary experimental, $\mathrm{Ab}$ initio quantum mechanics, Monte Carlo and molecular dynamics studies," Journal of Molecular Liquids, vol. 272, pp. 120-136, 2018.

[37] I. B. Obot and Z. M. Gasem, "Theoretical evaluation of corrosion inhibition performance of some pyrazine derivatives," Corrosion Science, vol. 83, pp. 359-366, 2014.

[38] G. Fan, H. Liu, B. Fan, Y. Ma, H. Hao, and B. Yang, "Trazodone as an efficient corrosion inhibitor for carbon steel in acidic and neutral chloride-containing media: facile synthesis, experimental and theoretical evaluations," Journal of Molecular Liquids, vol. 311, Article ID 113302, 2020.

[39] H. Liu, B. Fan, G. Fan, Y. Ma, H. Hao, and W. Zhang, "Anticorrosive mechanism of poly (N-ethylaniline)/sodium silicate electrochemical composites for copper: correlated experimental and in-silico studies," Journal of Materials Science \& Technology, vol. 72, pp. 202-216, 2021.

[40] H. Liu, B. Fan, G. Fan et al., "Long-term protective mechanism of poly(N-methylaniline)/phosphate one-step electropolymerized coatings for copper in $3.5 \% \mathrm{NaCl}$ solution," Journal of Alloys and Compounds, vol. 872, Article ID 159752, 2021.

[41] I. B. Obot, S. A. Umoren, Z. M. Gasem, R. Suleiman, and B. E. Ali, "Theoretical prediction and electrochemical evaluation of vinylimidazole and allylimidazole as corrosion inhibitors for mild steel in $1 \mathrm{M} \mathrm{HCl,"} \mathrm{Journal} \mathrm{of} \mathrm{Industrial} \mathrm{and}$ Engineering Chemistry, vol. 21, pp. 1328-1339, 2015.

[42] G. Gao and C. Liang, "Electrochemical and DFT studies of $\beta$-amino-alcohols as corrosion inhibitors for brass," Electrochimica Acta, vol. 52, no. 13, pp. 4554-4559, 2007. 